\title{
Determination of Excess Removability of Self-Adhesive Resin Cements
}

\section{Tran D*, Afutu R, Dunn K and Kugel G}

Tufts University School of Dental Medicine, USA

*Corresponding author: Duong Tran, DDS, MPH, PhD, Tufts University School of Dental Medicine, 1 Kneeland Street, room 1513B, Boston, MA, 02111, Tel: 6176363614; Email: Duong.Tran@tufts.edu

\section{Research Article \\ Volume 5 Issue 4}

Received Date: October 01, 2020

Published Date: October 14, 2020

DOI: $10.23880 /$ oajds-16000272

\section{Abstract}

Objective: This study aimed to determine the force required to remove a defined amount of self-adhesive resin cements excess from a (pretreated) dentin surface after tack curing.

Methods: Bovine teeth $(n=5)$ were ground flat to expose dentin, polished (grit 320 sandpaper), distilled water rinsed, and gently air-dried. With the aid of a drilling template fixed with superglue (Sekundenkleber, Renfert GmbH), 1 to 3 cylindrical cavities $(4.5 \pm 0.1 \mathrm{~mm}$ diameter $\times 2.0 \pm 0.1 \mathrm{~mm}$ depth) were drilled. Superglue was mechanically removed after drilling. Resin cement weighing $30 \mathrm{mg}$ was placed in the cavity and pushed through with a stainless-steel rod $(4.0 \pm 0.05 \mathrm{~mm}$ diameter $\mathrm{x}$ $2.0 \pm 0.1 \mathrm{~mm}$ height), so that all of the excess cement was pushed out onto one side of the cavity to form a half moon. Excess cement was cured for a defined time of 5 seconds, from a defined distance ( $2 \mathrm{~mm}$ spacer) from the tooth surface using an Elipar $^{\mathrm{TM}}$ S10 light curing device (3M ESPE). Excess cement was sheared off using a jig (Zwick Z010, n=5; speed= 0.75 mm $/ \mathrm{min}$ ). Maximum force $(\mathrm{N})$ to shear off the excess cement was recorded.

Results: Experimental Cement and Calibra ${ }^{\circledR}$ Universal were statistically lower in mean newton force than the other selfadhesive resin cements. TheraCem ${ }^{\circledR}$ Ca and RelyX $\mathrm{X}^{\mathrm{TM}}$ Unicem 2 were not statically different from each other. Maxcem Elite ${ }^{\mathrm{TM}}$ Chroma and G-CEM LinkAce ${ }^{\circledR}$ were statistically lower than TheraCem ${ }^{\circledR}$ Ca and RelyX ${ }^{\mathrm{TM}}$ Unicem 2.

Conclusion: A method was developed to quantify force needed to remove cement excess. Under standardized conditions, different levels of removal force were identified. PANAVIA ${ }^{\mathrm{TM}}$ SA Cement Plus, Calibra ${ }^{\circledR}$ Universal and Experimental Cement require a significantly lower force for excess removal. SpeedCEM ${ }^{\circledR}$ Plus and Maxcem Elite ${ }^{\mathrm{TM}}$ Chroma require an intermediate force. Rely $\mathrm{X}^{\mathrm{TM}}$ Unicem 2 and TheraCem ${ }^{\circledR}$ Ca require a significantly higher force to achieve excess removal. Excess removal force can be lowered by reducing irradiation time as shown with RelyX ${ }^{\mathrm{TM}}$ Unicem 2 (one second cure) and RelyX ${ }^{\mathrm{TM}}$ Unicem 2 (two second cure).

Keywords: Adhesive resin cements; Excess cement; Peri-implant diseases

Abbreviations: SARCs: Self-adhesive resin cements; SBS: Shear Bond Strength.

\section{Introduction}

While seating a restoration, such as a crown, excess cement is possibly formed around the margin. This residual excess cement on the tooth surface is likely to result in plaque accumulation, local inflammation and periodontal disease [1-6]. A systematic review of excess cement and the risk of peri-implant disease reported that prevalence of peri-implant diseases ranged from $1.9 \%$ to $75 \%$ for implants with cemented restorations, with proportions of $33-100 \%$ associated with excess cement [7]. Accurate and 
complete removal of excess cement around the margin after cementation is essential to reduce the risk of periodontal disease and increase longevity of the restorations.

Many manufacturers of self-adhesive resin cements (SARCs) state easy excess cement removal. According to manufacturers' instructions for use, SARCs will either selfcure or be tack-cured to initiate a gel phase during which the cements can be easily removed in one piece with explorer or scaler [8-12]. Tack cure window can be up to 10 seconds and the gel phase can last up to 45 seconds, giving dentist enough time to clean up the residual cement thoroughly [8]. A color cleanup indicator is also available in which its pink color fades off at the gel state to let dentist know the optimal time to cleanup excess cement [11]. However, there are still some cases of dentists accidentally light-cure SARCs longer than the necessary tack-curing time, the cements harden and cannot be removed with a hand instrument anymore. Removing the hardened cements is very difficult and messy, especially in the posterior interproximal areas. Residual cements may increase the risk of dental plaque accumulation and gingival inflammation.

In addition, each material has its own ability to remove at different forces depending on the chemical composition of the material. Although manufacturers generally state easy removal of excess cements, they do not quantify the force needed to remove the cements after tack curing. The removing forced can be measured through the shear bond strength (SBS) test of SARCs to enamel/dentin. Many studies have assessed the SBS of SARCs to enamel/dentin after complete hardening. However, there has been little literature reporting and comparing the removing force between cements after tack curing. This study aimed to determine the force required to remove a defined amount of self-adhesive resin cements excess from a (pre-treated) dentin surface after tack curing.

\section{Materials and methods}

\section{Test Self-Adhesive Resin Cements}

The popular self-adhesive cements were evaluated in this in-vitro study, including Calibra ${ }^{\circledR}$ Universal, Experimental Cement, G-CEM LinkAce ${ }^{\circledR}$, Maxcem Elite $^{\mathrm{TM}}$ Chroma, PANAVIA $^{\text {TM }}$ SA Cement Plus, SpeedCEM ${ }^{\circledR}$ Plus, TheraCem ${ }^{\circledR}$ Ca, RelyX ${ }^{\text {TM }}$ Unicem 2, RelyX ${ }^{\text {TM }}$ Unicem 2 (one second cure), RelyX ${ }^{\mathrm{TM}}$ Unicem 2 (two second cure) (Table 1). These cements are self-etching materials which don't require additional etchant or adhesive. Their main components include the predominant functional acidic monomers, conventional dimethacrylate monomers (eg: bis-GMA, UDMA, and TEGDMA), filler particles, and activator-initiator systems [13].

\begin{tabular}{|c|c|c|}
\hline Cements & Abbreviations & Manufacturer \\
\hline Calibra $^{\circledR}$ Universal & $\mathrm{CU}$ & Dentsply \\
\hline Experimental Cement & EXP & 3M/ESPE \\
\hline G-CEM LinkAce ${ }^{\circledR}$ & GCEM & GC Corporation \\
\hline Maxcem Elite ${ }^{\mathrm{TM}}$ Chroma & MAX & Kerr \\
\hline PANAVIA $^{\mathrm{TM}}$ SA Cement Plus & PAN & Kuraray Noritake Dental \\
\hline SpeedCEM ${ }^{\circledR}$ Plus & SCP & Ivoclar Vivadent \\
\hline TheraCem $^{\circledR} \mathrm{Ca}$ & $\mathrm{TC}$ & BISCO Inc \\
\hline RelyX ${ }^{\mathrm{TM}}$ Unicem 2 & RXU2 & 3M/ESPE \\
\hline RelyX ${ }^{\mathrm{TM}}$ Unicem 2 (two second cure) & RXU2a & 3M/ESPE \\
\hline RelyX ${ }^{\mathrm{TM}}$ Unicem 2 (one second cure) & RXU2b & 3M/ESPE \\
\hline
\end{tabular}

Table 1: List of self-adhesive resin materials used and abbreviations.

The Calibra ${ }^{\circledR}$ Universal self-adhesive resin cement provides dentist a plenty of time for an easy excess cement cleanup [8]. It creates a strong initial bond after cementation and has a wide range of indications, from metal crowns and PFMs, to all-zirconia and all-ceramic. The Experimental Cement is a novel self-adhesive cement developed by 3M/ ESPE. G-CEM LinkAce ${ }^{\circledR}$ incorporates glass ionomer and $7^{\text {th }}$ generation adhesive technologies providing consistent high bond strengths for both moist and dry conditions, low thermal expansion, and minimal post-operative sensitivity [10]. It is indicated for luting of all-ceramic, metal or composite indirect restorations as well as endodontic posts. Maxcem Elite $^{\mathrm{TM}}$ Chroma has a color cleanup indicator for removal of excess cement, a high bond strength, and is compatible with all indirect restorations, ceramics, PFMs, metal restorations, and CAD/CAM block materials [11]. PANAVIA ${ }^{\mathrm{TM}}$ SA Cement Plus contains two types of adhesive monomers ("MDP" and "LCSi") allowing a strong, durable chemical bond to 
porcelain, lithium disilicate and composite resin without primer treatment [14]. SpeedCEM ${ }^{\circledR}$ Plus is a self-adhesive, self-curing resin cement with optional light-curing. It is indicated for the permanent seating of restorations made of zirconium oxide and metal-ceramics and for the cementation of restorations on implant abutments [12]. TheraCem ${ }^{\circledR} \mathrm{Ca}$ is a dual-cured, calcium releasing, self-adhesive resin cement indicated for luting crowns, bridges, inlays, onlays and posts [15]. RelyX $\mathrm{X}^{\mathrm{TM}}$ Unicem 2 is dual cure, strong and moisturetolerant, easy removal of excess, and suitable for a cementing a wide range of restorations, including all-ceramic, composite or metal inlays, onlays, crowns and bridges [16].

\section{Sample Preparations}

Bovine teeth $(n=5)$ were ground flat to expose dentin and polished with grit 320 sandpaper. After polishing, the samples were rinsed with distilled water and gently airdried. A drilling template was fixed on the exposed dentin with superglue (Sekundenkleber, Renfert $\mathrm{GmbH}$ ). With the aid of the template, 1 to 3 cylindrical cavities $(4.5 \pm 0.1 \mathrm{~mm}$ diameter x $2.0 \pm 0.1 \mathrm{~mm}$ depth) were drilled into the dentin. Superglue was mechanically removed after drilling. Resin cement weighing $30 \mathrm{mg}$ was placed in the cavity and pushed through with a stainless-steel rod $(4.0 \pm 0.05 \mathrm{~mm}$ diameter x $2.0 \pm 0.1 \mathrm{~mm}$ height), so that all of the excess cement was pushed out onto one side of the cavity to form a half moon (Figures $1 \& 2$ ). Excess cement was cured for a defined time of 5 seconds, from a defined distance ( $2 \mathrm{~mm}$ spacer) from the tooth surface using an Elipar ${ }^{\mathrm{TM}}$ S10 light curing device (3M ESPE) (Figures $3 \& 4$ ). In addition to the Rely $\mathrm{X}^{\mathrm{TM}}$ Unicem 2 group cured for 5 seconds, two groups of RelyX ${ }^{\mathrm{TM}}$ Unicem 2 were also included with curing times of 1 and 2 seconds. Excess cement was sheared off using a jig (Zwick Z010, n=5; speed $=0.75 \mathrm{~mm} / \mathrm{min}$ ) (Figures $5 \& 6$ ). Maximum force $(\mathrm{N})$ to shear off the excess cement was recorded.

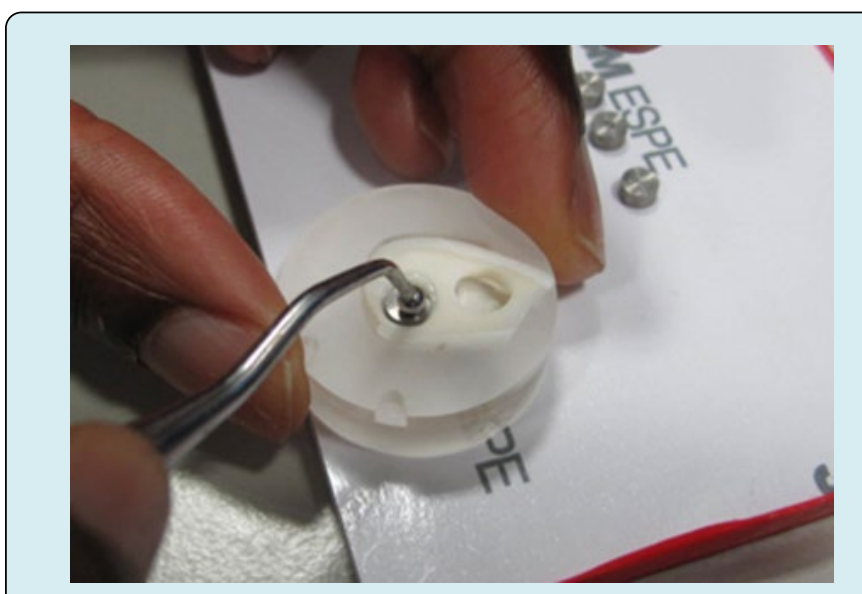

Figure 1: Stainless steel rod placed in prepared cavity contained with $30 \mathrm{mg}$ of resin cement.

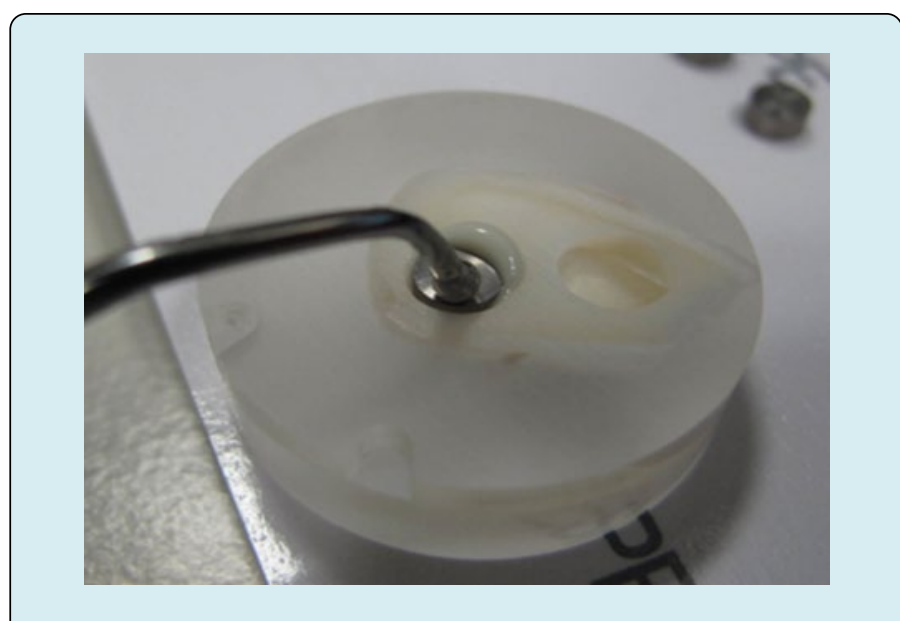

Figure 2: Stainless steel rod pushed to the side to form a half moon.

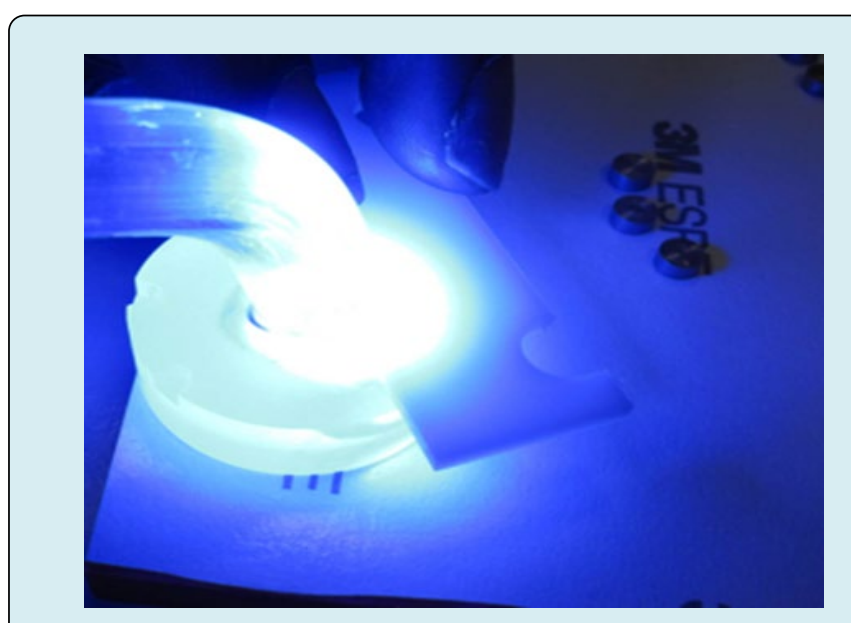

Figure 3: Excess resin cement (half-moon) cement light cured for a defined time with a standard distance of $2 \mathrm{~mm}$.

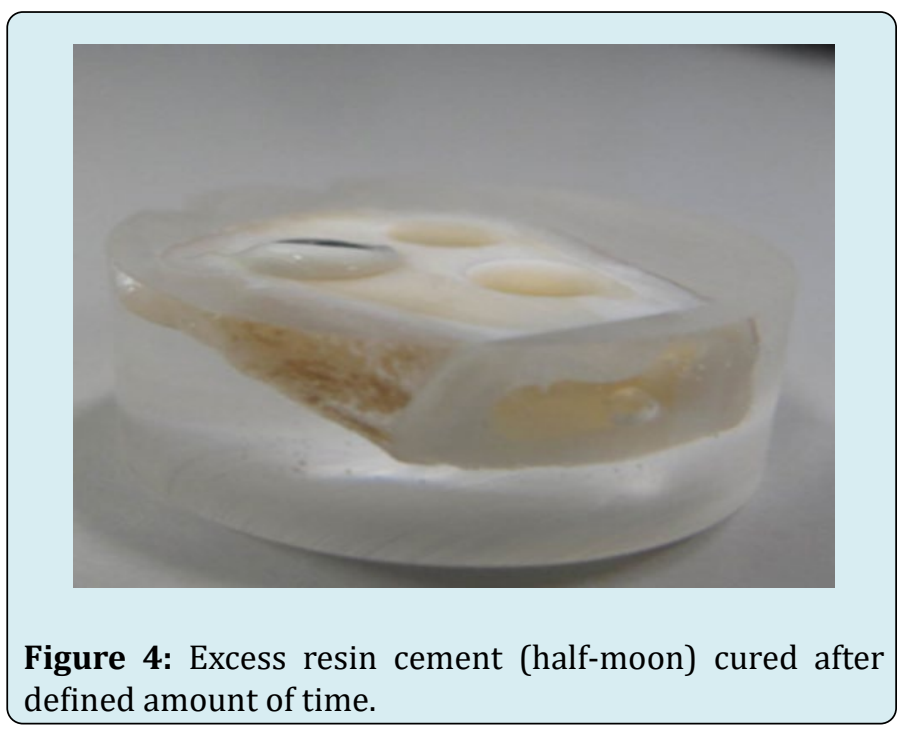



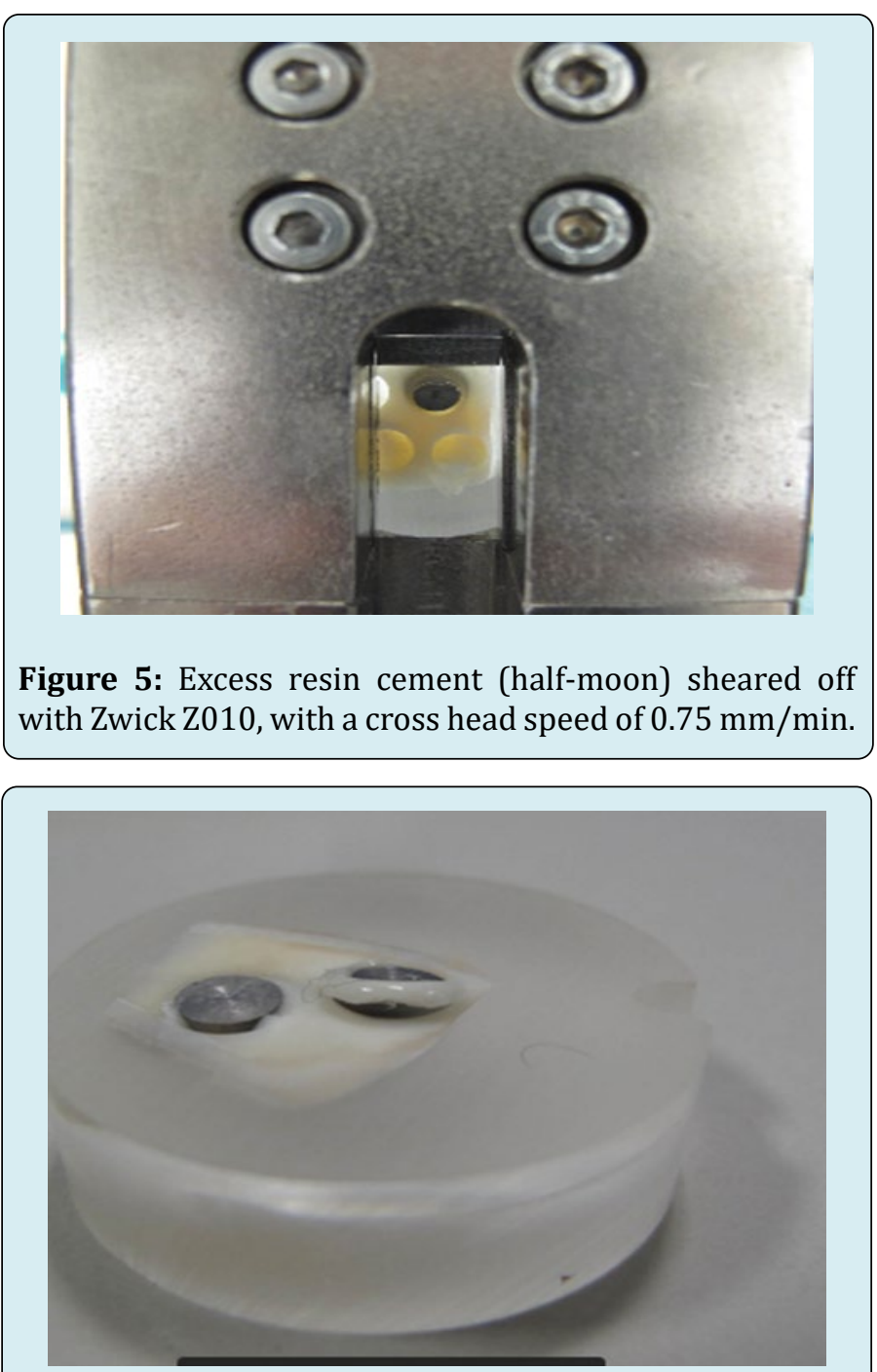

Figure 6: Specimen post-shear bond testing.

\section{Results}

Removing force for resin cement materials after tackcuring ranged from 10 to $56.3 \mathrm{~N}$ (Table 2 \& Figure 7). Among the tested cements, Calibra ${ }^{\circledR}$ Universal has the lowest removing force $(10.0 \pm 2.0 \mathrm{~N})$ while RelyX ${ }^{\mathrm{TM}}$ Unicem 2 has the highest removing force $(56.3 \pm 9.2 \mathrm{~N})$. Experimental Cement and Calibra ${ }^{\circledR}$ Universal were statistically lower in mean newton force than the other self-adhesive resin cements. TheraCem ${ }^{\circledR}$ Ca and RelyX ${ }^{\mathrm{TM}}$ Unicem 2 were not statically different from each other. Maxcem Elite $^{\mathrm{TM}}$ Chroma and G-CEM LinkAce ${ }^{\circledR}$ were statistically lower than TheraCem ${ }^{\circledR} \mathrm{Ca}$ and RelyX ${ }^{\mathrm{TM}}$ Unicem 2.

\begin{tabular}{|c|c|c|}
\hline Cements & $\begin{array}{c}\text { Irradiation } \\
\text { Time (s) }\end{array}$ & $\begin{array}{c}\text { Force }(\mathrm{N}) \text { of } \\
\text { cement excess } \\
\text { removal }\end{array}$ \\
\hline Calibra ${ }^{\circledR}$ Universal & 5 & $10.0 \pm 2.0^{\mathrm{E}}$ \\
\hline $\begin{array}{c}\text { Experimental } \\
\text { Cement }\end{array}$ & 5 & $14.4 \pm 3.6^{\mathrm{E}}$ \\
\hline G-CEM LinkAce ${ }^{\circledR}$ & 5 & $36.8 \pm 6.7^{\mathrm{BC}, \mathrm{D}}$ \\
\hline $\begin{array}{l}\text { Maxcem Elite }{ }^{\mathrm{TM}} \\
\text { Chroma }\end{array}$ & 5 & $31.3 \pm 6.4^{\mathrm{C}, \mathrm{D}}$ \\
\hline $\begin{array}{l}\text { PANAVIA }^{\mathrm{TM}} \text { SA } \\
\text { Cement Plus }\end{array}$ & 5 & $11.3 \pm 2.1^{\mathrm{E}}$ \\
\hline SpeedCEM $^{\circledR}$ Plus & 5 & $21.6 \pm 5.6^{\mathrm{D}, \mathrm{E}}$ \\
\hline TheraCem ${ }^{\circledR} \mathrm{Ca}$ & 5 & $50.9 \pm 8.0^{\mathrm{A}, \mathrm{B}}$ \\
\hline RelyX ${ }^{\mathrm{TM}}$ Unicem 2 & 5 & $56.3 \pm 9.2^{\mathrm{A}}$ \\
\hline RelyX ${ }^{\mathrm{TM}}$ Unicem 2 & 2 & $42.02 \pm 17.5^{\mathrm{D}, \mathrm{E}}$ \\
\hline RelyX ${ }^{\mathrm{TM}}$ Unicem 2 & 1 & $21.0 \pm 2.7^{\mathrm{A}, \mathrm{B}, \mathrm{C}}$ \\
\hline
\end{tabular}

Table 2: Force (N) of Excess Removal of Self- Adhesive Resin Cement.

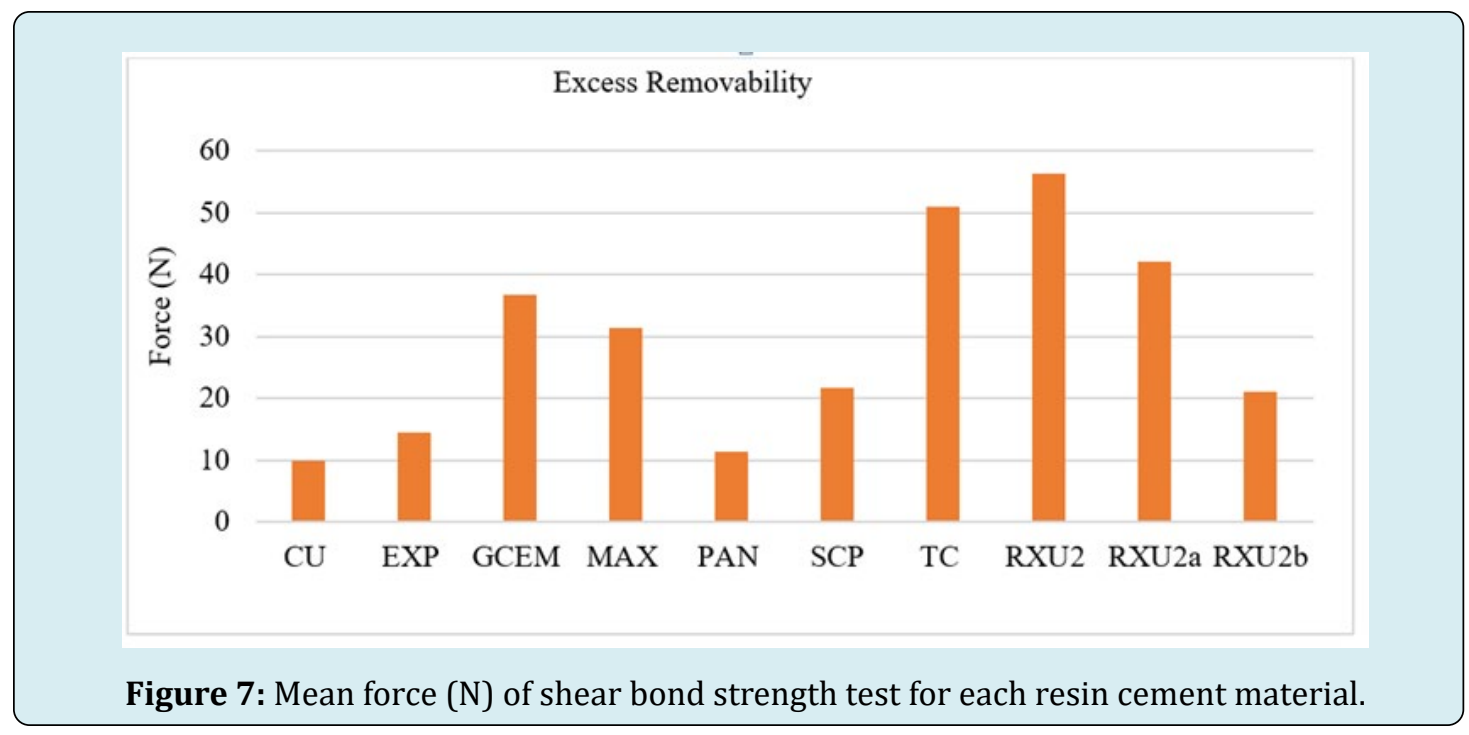




\section{Open Access Journal of Dental Sciences}

Data is presented as means \pm standard deviations. Means that do not share the same superscript letter in a column are significantly different. Data was compared using ANOVA (with post-hoc Tukey) with $\alpha=0.05$.

\section{Discussion}

Given the importance of desirable handling characteristics of dental cements to the dentists, this study presented a novel method to quantify and compare the removing forces of the tested SARCs after tack-curing. The removing forces after tack-curing ranged from $10 \mathrm{~N}$ for Calibra ${ }^{\circledR}$ Universal to $56.3 \mathrm{~N}$ for RelyX ${ }^{\mathrm{TM}}$ Unicem 2, indicating the level of easiness of excess cement removal. It is assumed that the higher the force, the more difficult to remove the excess cement. Therefore, quantification of the force after tack-curing is an essential information of an SARC in helping dentist selecting a cement which can be removed easily.

To the authors' best knowledge, there has been little body of literature reporting removing force after tack-curing cements. Many studies assessed the effect of tack-curing on the degree of conversion and mechanical properties of SARCs [17-19]. Other studies reported shear bond strength of cements after final cure which does not necessarily indicate the level of cement removal easiness after tack-curing [2024]. In 2017, a survey was conducted on 41 dentists to assess a novel cement of $3 \mathrm{M}$ company regarding the speed of excess cement clean-up associated with tack light-cure option20. Majority of the dentists stated a strong preference for the ease $(92.6 \%)$ and speed of excess cement clean-up (87.8\%) after tack-curing. A clinical case example was also presented for Calibra ${ }^{\circledR}$ Universal to feature its wide tack-cure window and extended gel phase for easier cleanup [8].

Our study recorded the highest removing force after tack curing for RelyX ${ }^{\mathrm{TM}}$ Unicem 2 ( 5 second cure) followed by TheraCem ${ }^{\circledR} \mathrm{Ca}$, RelyX ${ }^{\mathrm{TM}}$ Unicem 2 ( 5 second cure), Rely $\mathrm{X}^{\mathrm{TM}}$ Unicem 2 ( 2 second cure), G-CEM LinkAce ${ }^{\circledR}$, Maxcem Elite $^{\mathrm{TM}}$ Chroma, RelyX $\mathrm{X}^{\mathrm{TM}}$ Unicem 2 (1 second cure), Experimental Cement, PANAVIA ${ }^{\mathrm{TM}}$ SA Cement Plus, and Calibra ${ }^{\circledR}$ Universal. The reported shear bond strength (SBS) to zirconia after final curing of the SARCs in descending order is also RelyX ${ }^{\mathrm{TM}}$ Unicem 2, TheraCem ${ }^{\circledR}$ Ca, G-CEM LinkAce ${ }^{\circledR}$, Maxcem Elite $^{\mathrm{TM}}$ Chroma, PANAVIA ${ }^{\mathrm{TM}}$ SA Cement Plus, and Calibra ${ }^{\circledR}$ Universal $[16,25,26]$. Although the removing forces after tack curing are not equal to the SBS, the similarity in descending order between them still indicates the validity of our novel method because it is reasonable to assume that the higher the SBS after final curing, the higher the removing force after tack curing.

According to the manufacturers, the tested SARCs in our study have different windows for tack-curing. For example,
Calibra ${ }^{\circledR}$ Universal provides a wide tack cure window of up to 10 seconds [9] while G-CEM LinkAce ${ }^{\circledR}$ and PANAVIA SA Cement Plus recommend tack cure windows of 1 second, and $2-5$ seconds, respectively $[10,14]$. Curing longer than the recommended tack cure window may cause the cements to become harden and increase the removing force. We found that the removing force increase with the tack curing time when RelyX ${ }^{\mathrm{TM}}$ Unicem 2 was cured for 1, 2, and 5 seconds (Table 2 \& Figure 7). The interruption of the tack curing at an inappropriate time may result in a low cross-link density of the luting cement, resulting higher susceptibility to wear and may be the bond to the tooth structure [27]. However, for a fair comparison between different cements, a 5-second tack cure was applied for all cement except for RelyX ${ }^{\mathrm{TM}}$ Unicem 2 which was additionally tack cured for 1 and 2 seconds.

\section{Conclusion}

A method was developed to quantify force needed to remove cement excess. Under standardized conditions, different levels of removal force were identified. PANAVIA ${ }^{\mathrm{TM}}$ SA Cement Plus, Calibra ${ }^{\circledR}$ Universal and Experimental Cement require a significantly lower force for excess removal. SpeedCEM $^{\circledR}$ Plus and Maxcem Elite ${ }^{\mathrm{TM}}$ Chroma require an intermediate force. RelyX ${ }^{\mathrm{TM}}$ Unicem 2 and TheraCem $^{\circledR} \mathrm{Ca}$ require a significantly higher force to achieve excess removal. Excess removal force can be lowered by reducing irradiation time as shown with RelyX ${ }^{\mathrm{TM}}$ Unicem 2 (one second cure) and RelyX $\mathrm{X}^{\mathrm{TM}}$ Unicem 2 (two second cure).

\section{References}

1. Chee WW, Duncan J, Afshar M, Moshaverinia A (2013) Evaluation of the amount of excess cement around the margins of cement-retained dental implant restorations: the effect of the cement application method. J Prosthet Dent 109(4): 216-221.

2. Korsch M, Obst U, Walther W (2014) Cement-associated peri-implantitis: a retrospective clinical observational study of fixed implant-supported restorations using a methacrylate cement. Clin Oral Implants Res 25(7): 797802.

3. Korsch M, Robra BP, Walther W (2015) Cementassociated signs of inflammation: retrospective analysis of the effect of excess cement on peri-implant tissue. Int J Prosthodont 28(1): 11-18.

4. Korsch M, Walther W, Bartols A (2017) Cementassociated peri-implant mucositis. A 1-year follow-up after excess cement removal on the peri-implant tissue of dental implants. Clin Implant Dent Relat Res 19(3): 523-529. 
5. Pesce P, Canullo L, Grusovin MG, de Bruyn H, Cosyn J, et al. (2015) Systematic review of some prosthetic risk factors for periimplantitis. J Prosthet Dent 114(3): 346350 .

6. Wilson TG (2009) The positive relationship between excess cement and peri-implant disease: a prospective clinical endoscopic study. J Periodontol 80(9): 13881392.

7. Staubli N, Walter C, Schmidt JC, Weiger R, Zitzmann NU (2017) Excess cement and the risk of peri-implant disease - a systematic review. Clin Oral Implants Res 28(10): 1278-1290.

8. Goodchild JH (2016) Convenient Cleanup with Calibra Universal for Easier Cementation. Dent Today 35(6): 38.

9. (2018) Dentsply Sirona Calibra cement.

10. (2020) GC America Inc. G-CEM LinkAce.

11. (2020) Kerr Corporation. Maxcem Elite ${ }^{\mathrm{TM}}$ Chroma.

12. Ivoclar Vivadent Inc. SpeedCEM Plus.

13. Manso AP, Carvalho RM (2017) Dental Cements for Luting and Bonding Restorations: Self-Adhesive Resin Cements. Dent Clin North Am 61(4): 821-834.

14. (2020) Kuraray Noritake. Panavia SA Cement Universal.

15. (2020) Bisco. The Future is here with the "Next Generation Cement".

16. (2020) 3M. RelyX ${ }^{\mathrm{TM}}$ Unicem 2 Self-Adhesive Resin Cement.

17. Stegall D, Tantbirojn D, Perdigão J, Versluis A (2017) Does Tack Curing Luting Cements Affect the Final Cure? J Adhes Dent 19(3): 239-243.

18. Yang B, Huang Q, Holmes B, Guo J, Li Y, et al. (2020) Influence of curing modes on the degree of conversion and mechanical parameters of dual-cured luting agents. J Prosthodont Res 64(2): 137-144.

19. Asmussen E, Peutzfeldt A (2003) Two-step curing: influence on conversion and softening of a dental polymer. Dent Mater 19(6): 466-470.

20. Falsafi A, Bui H, Worms C, Dylan J, Anke B, et al. (2018) Clinical Evaluation of Novel Temporary Cement: ExcessCement and Remnant Removals.

21. Chai J, Chu FC, Chow TW, Liang BM (2008) Shear bond strength between nickel-chromium and human dentine using a dual-cure, self-adhesive universal resin luting agent. Eur J Prosthodont Restor Dent 16(2): 85-88.

22. Dimitriadi M, Zafiropoulou M, Zinelis S, Silikas N, Eliades G (2019) Silane reactivity and resin bond strength to lithium disilicate ceramic surfaces. Dent Mater 35(8): 1082-1094.

23. Lee JJ, Kang CK, Oh JW, Seo JM, Park JM (2015) Evaluation of shear bond strength between dual cure resin cement and zirconia ceramic after thermocycling treatment. J Adv Prosthodont 7(1): 1-7.

24. Stewart GP, Jain P, Hodges J (2002) Shear bond strength of resin cements to both ceramic and dentin. J Prosthet Dent 88(3): 277-284.

25. Chen L, Gleave C, Suh B (2017) New Self-adhesive Resin Cement with Alkaline $\mathrm{pH}$

26. Wiedig C, Guggenberger R, Ludsteck M, Rennschmid H, Raia G, et al. (2011) Material Properties of Self-adhesive Resin Cements.

27. Niemi A, Perea Lowery L, Alaqeel SM, Ramakrishnaiah R, Vallittu PK (2020) Dual-curing resin cement with colour indicator for adhesively cemented restorations to dental tissues: Change of colour by curing and some physical properties. Saudi J Biol Sci 27(1): 395-400. 